\title{
DIY materials from potato skin waste for design
}

\section{Clarita Caliendo* and Carla Langella}

\author{
DICDEA,
}

Universita degli Studi della Campania 'Luigi Vanvitelli', via Roma 29, 81031 Aversa (CE), Italy

Email: c.caliendo@hotmail.it

Email: carla.langella@unicampania.it

*Corresponding author

\section{Carlo Santulli}

School of Architecture and Design,

Universita degli Studi di Camerino,

Viale della Rimembranza, 63100 Ascoli Piceno, Italy

Email: carlo.santulli@unicam.it

\begin{abstract}
This work concerns the creation of a wall display for fruits, made in a DIY material structure, as the result of a 'material tinkering' process over waste to enable understanding possible application in a design context. The material and object is obtained starting from potato skins, as an example of waste very frequent in the food processing chain, in most local contexts. The display is specifically designed in a double layer configuration, partially translucent, coloured with food dyes and aromatised during the experimentation phase to ensure its suitability to the purpose. Some basic characterisation tests were also performed to allow for the possible development of a customised product from this material demonstrator. The process, in giving some value to a typical and very diffuse food chain waste, would therefore guarantee the upcycling of the relevant refuse. The structure is intended for application into a context of farm holiday site and aimed at presenting local products, ideally coming from the very farm fields involved.
\end{abstract}

Keywords: potato skin waste; material tinkering; fruit display; DIY material.

Reference to this paper should be made as follows: Caliendo, C., Langella, C. and Santulli, C. (XXxx) 'DIY materials from potato skin waste for design', Int. J. Sustainable Design, Vol. X, No. Y, pp.xxx-xxx.

Biographical notes: Clarita Caliendo is an Industrial Designer and currently working in a company producing polystyrene, for the realisation of new projects using waste. She graduated in Design and Communication in 2013 at the University of Campania "Luigi Vanvitelli". She subsequently obtained her Master's degree in Design for Innovation in 2016 at the Polytechnic School of Basic Sciences, in Aversa. During these years, she has participated in several competitions, winning first prizes in some of these and has participated in various exhibitions and events exposing projects and samples of materials made by her.

Carla Langella is an Architect and Assistant Professor of Industrial Design at UniversitàdegliStudi of Campania "Luigi Vanvitelli", Department of Architecture and Industrial Design (DADI), where she lectures "Product 
Design", "Bio-Innovation Design" and "Design for visualization of the Science”. Since 2006, she has founded and coordinates the Hybrid Design Lab (www.hybriddesignlab.unicampania.it), a design laboratory dedicated to the mutual collaboration between design and science with particular attention to the human centred innovation. Her publications and research projects are related to the themes of biomimetic design, design of new materials and application of sustainable tools in design innovation.

Carlo Santulli is an Associate Professor of Materials Science and Technology, UniversitàdegliStudi di Camerino. His research interests are on composite materials, sustainable materials, waste upcycling, bio-inspired design and biomimetics. He has been working in Sapienza Università di Roma, JRC Ispra, University of Liverpool, where he received his $\mathrm{PhD}$, University of Nottingham, University of Reading and SecondaUniversità di Napoli. He has been invited Researcher and Professor at KatholiekeUniversiteit Leuven, Ecole des Mines de Saint Etienne, Université de Rouen, Università di Bologna, Università di Perugia and UniversitiTeknologi Malaysia. He also acts as a divulgator of environmental and sustainability themes.

\section{Introduction}

In the past, for example in the Renaissance, art and science were not perceived as different concepts, even opposing to each other, but rather as an interconnected discipline: it was not unusual that a person, such as Leonardo da Vinci, could demonstrate the highest skills in a number of different fields. However, at the moment in which an increasing specialisation took place, this possibility was more and more excluded. This is detrimental nonetheless for processes, such as design, which require using together scientific and technological skills with inspiration coming from creativity. Designers have in last decades obtained an increased access to technological processes and production, while on the other side they explore operatively the world of materials. The latter have therefore gradually been organised with classifications that, starting from engineering properties (e.g., mechanical, thermal, physico-chemical), more recently were extended also to expressive characteristics, as reflected also in the progressive development and use of Ashby et al.'s (2013) diagrams. This means that materials, their use and combination in design objects have been defined with increasing precision and repeatability in terms of their capability to communicate a sense. According to what suggested by Oxman (2010): “We're not only designing form, we're also designing behavior, and that's what I see as a super big deal'. In other words, 'designing behavior" means recognising to any material a kind of 'personality', which is expressed in the context of use, normally in relation with a design object and its application.

In the present context, moving towards a 'circular economy' includes the objective of eliminating waste or rather envisaging a complete use of it to the highest possible level (Bodzay and Banhegyi, 2016). According to recent EU guidelines, such as Directive 2008/98/EC, waste is defined as a 'secondary raw material'. End-of-life criteria distinguish between waste and by-products: in practical terms, waste is defined as such only in case it is explicitly declared to be. This suggests the importance to create methods to prevent the production of waste. A possibility is to offer to prospective 'waste' a use and a time frame compatible with its nature, while conferring to it some added value: this 
procedure is commonly defined as 'upcycling'. It is clear that the creation of 'single use' objects is excluded in this context and therefore the attention to waste 'personality' needs to be thorough, involving a sound reflection on possibilities 'embedded' into its nature.

The production of DIY materials is an important exercise to elucidate the assets and limitations of waste upcycling. Its value has been also recognised as significant also in pedagogical terms, e.g., to introduce children to the knowledge of materials and their use in design and the development of good practices in differentiated waste collection (Santulli and Lucibello, 2018). In this sense, a number of projects do exist, which are based on the concept of upcycling waste: with these the present project shares some characteristics. In general terms, these projects explore the nature of waste and investigate whether likeable objects can be produced from it. This would allow restoring a kind of 'affection bond' with the user: if such a bond is created, waste may rather become a by-product, therefore with some prospective use in design objects.

In 'Gumdrop' (by Anna Bullus, 2008), chewing gums are recycled initially into pink receptacles designed specifically for the disposal of chewed gums, then also in a variety of other products, such as wellington boots, mobile phone covers, stationery objects, packaging, etc. AgriDust by Marina Ceccolini (2015) is a project of recovery and valorisation of waste fruit and vegetables, based on six types of food-derived waste (exhaust coffee grounds, peanut shells, tomato skins, bean pods, orange peels and lemon peels), obtaining a biodegradable material with a process using non-toxic chemicals. The material is constituted for the $64.5 \%$ from waste and the remaining $35.5 \%$ by a binder in basis of potato starch. 3D printer filament, AgriDust can be used to create pots for plants and packaging, and is proposed as material for 3D printing, replacing the extruder by a syringe. Another example is 'Orange Fiber' by Adriana Santanocito and Enrica Arena (2011) which results in sustainable textile from citrus byproducts for fashion uses. The aspect of obtaining a yarn as an example of interconnected structure is offered for example by Greetje Van Tiem (2012), which is based upon turning old newspapers into yarn that can be woven into carpets, curtains and upholstery, or in the case of Carmen Hijosa (2014), 'Pinatex', leather-replacing material from pineapple leaves fibres or in 'PaperMilk' by Susanna Bonati (2011), produced with milk fibres, cotton linters and fibres of pure virgin (alpha) cellulose. In 'Artichair' by Spyros Kizis (2014), a durable chair is obtained from artichoke waste and a biological resin produced mainly from waste cooking oil, while in 'Recycle Series' by Bentu Design (2015), lamps are built using construction and demolition waste (CDW).

In other cases, however, objects with shorter lifespan are obtained, yet biodegradable: the attention appears therefore more concentrated on the end-of-life than on the 'personality' or expressive character of waste. This is the case for example with 'NewspaperWood' by Meike Maijer (2010), which reverses a traditional production process, not from wood to paper, but from (news)paper to wood, so that the layers of paper appear like wood grain or growth rings of a tree therefore mimicking the aesthetics of real wood. In some cases even more philosophical instances as regards end-of-life are considered, such as with Paul Luckham-Manel Torres (2011), 'Spray-on' spray-on clothing that can be worn, washed and worn again, a mixture of short fibres in a solvent, allowing them to be sprayed at high pressure on the body. Luca Scarpellini (2009), 'UseDesign' even deals with the past life of the abandoned objects, a life to be finally wiped out: a kind of 'first class funeral', giving birth to brand new objects from the ashes of the old ones. A good example of this procedure is Anacleto, a stylish birds' feeder, 
designed by Luca Scarpellini for IFU. Other examples are 'Jelloware' by Ann Tucker, Chelsea Briganti, Monica Bhatia and Ingrid Zweifel (2013), edible cups in agar agar, 'Bioplastic Fantastic' by Johanna Schmeer (2016), where enzyme-enhanced bioplastics could produce essential nutrients as a substitute for traditional food resources that could soon run out. The self-development of the biodegradable material stands at the centre of 'Ecovative' mushroom mycelium packaging by Eben Bayer and Gavin McIntyre (2016), and 'Metabolic Factory', by Thomas Vailly (2012), using human hair bioplastics with glycerin and sodium sulphate.

With respect to the above cases, the present project is centred on a single refuse, i.e., potato skins, with the idea of producing a material demonstrator, able to ensure expressive potential, by different colours and aromas, and possibly a long lifespan, or else an easy reproducibility of the object. To ensure this, a DIY material approach, defined as 'material tinkering', is used, which is illustrated more into depth in the following section.

\section{DIY materials from waste}

Different routes have been followed so far for producing materials from waste. A possibility is for example the direct integration of waste, which has been attempted in the case of spinach waste and cocoa pod husk by digesting these in trifluoroacetic acid (TFA), casting, and evaporation. In this way, amorphous cellulose-based plastics are formed (Bayer et al., 2014). A first example of integration into the productive system is offered by the product developed in Figure 1, where a chocolate candy holder is obtained by the introduction of $30 \%$ cocoa pods waste into a polycaprolactone (PCL) biodegradable matrix. In this case, the relation with the productive system is clearly visible. On the other side, the object has limited sense as a 'single use' one, therefore the structure is designed to promote re-use with other candies over time.

Figure 1 'Chocolate candy’ holder (see online version for colours)
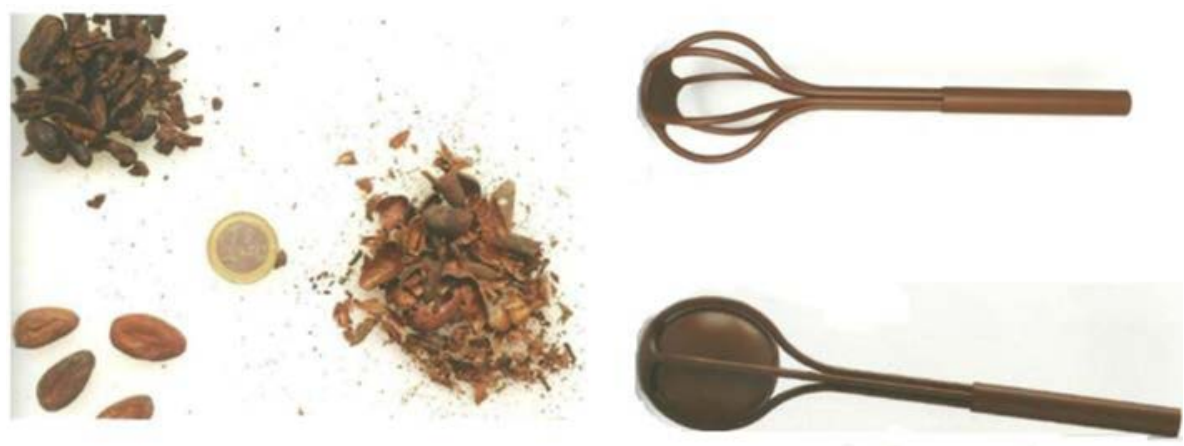

The above cases have some sense as they do reflect the same problem here treated. However, the development of DIY materials, which became a recent trend, widely witnessed in literature and over the internet, has slightly different objectives. The idea of this process, more than offering immediately a product ready to be marketed, is allowing designers experimenting over the potential of employing some materials, most frequently derived from previous use, such as waste, in an upcycling procedure. What is initially 
obtained is a material 'demonstrator', which is also the objective of the present experimentation, based in this specific case on the use of potato skins waste. A collection of significant cases, centred on the use of waste for their production has been reported in Rognoli et al. (2015): this process has been defined as 'material tinkering' (Parisi et al., 2017). This practice enables an improved comprehension of the material. In particular, the production of DIY materials from waste has obtained quite some interest in recent years. The number of examples tends to become countless and this may obviously have an environmental significance, by reducing the amount of waste disposed in other competitive practices, such as thermovalorisation, therefore diminishing also the 'carbon footprint' (Piemonte, 2011).

Figure 2 Tablecloth from paper obtained by grapevine marcs (see online version for colours)

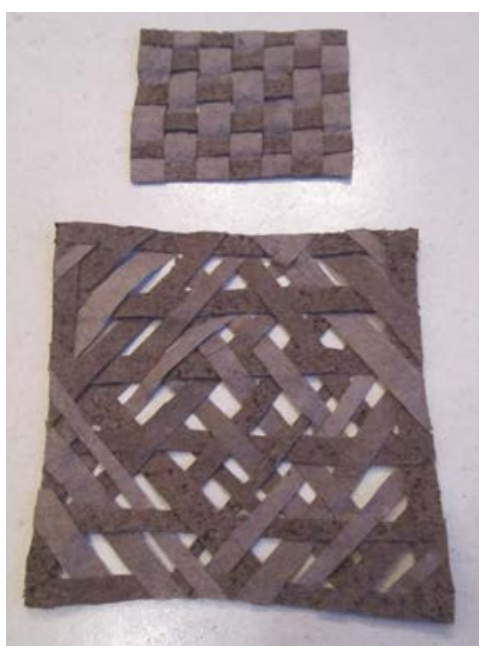

Source: Federica Palazzo

Figure 3 Handles for cutlery and knobs for pot lids in coffee grounds-based bioplastics (see online version for colours)

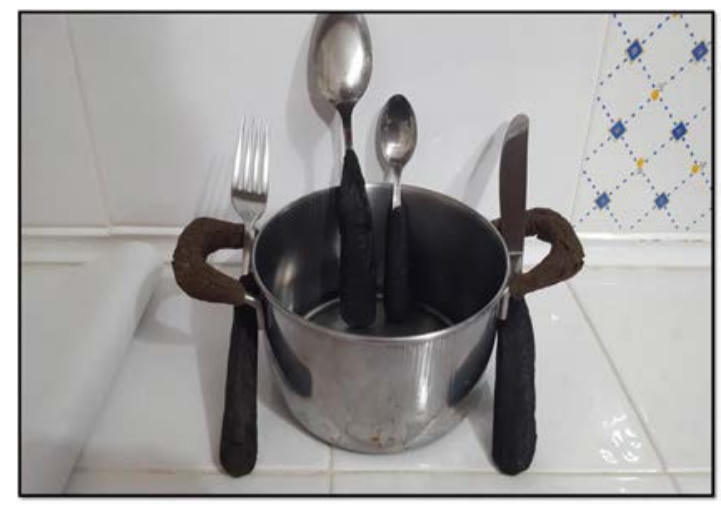

Source: Francesca D’Aprile 
DIY materials offered interesting possibilities recently, for example in the case of marc, residues from grapes pressing, from which small tablecloths were developed, serving in the case of winemaking fairs or similar events (Figure 2) (Arvanitoyannis et al., 2006). In other cases though, a real bioplastic, therefore easily mouldable, is developed from a purposely studied recipe, such as it is the case of the project whose results are exposed in Figure 3, concerning coffee grounds waste enclosure into a potato starch-based matrix for objects to be used in a kitchen context. The limit of the project was that the bioplastic is not fully impermeable to water and its strength is affected by the use of detergents and obviously is not suitable for introduction into a dishwasher. However, an easy replacement is ensured, as well as their possible reproduction. In other instances, DIY materials did serve to study some specific characteristics, such as translucency: this was for example the case of the one in Figure 4, where selected waste was based on discarded fibres from the harder and therefore normally not consumed part of fennels.

Figure 4 Lampshade in DIY material including fennel waste (see online version for colours)

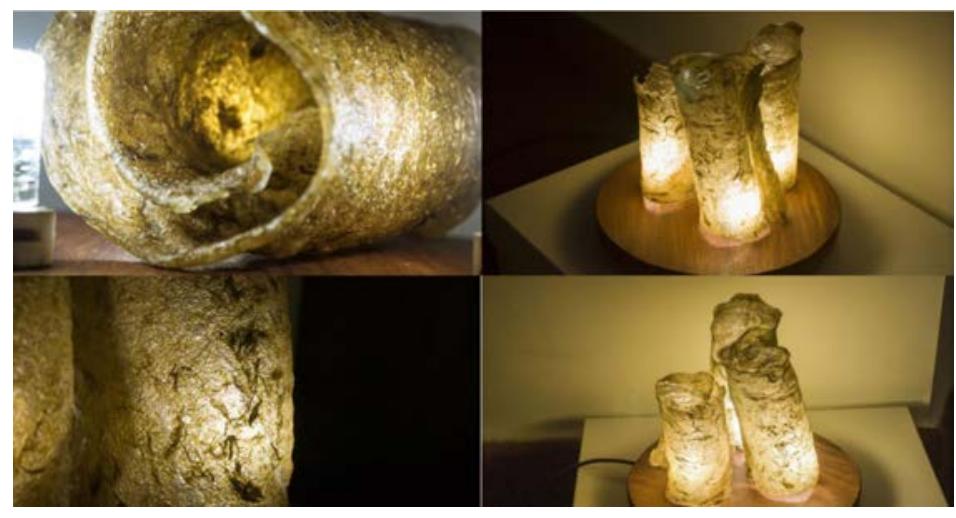

Source: Fabrizia Stacchiotti, Cesare Cellini, Fabio Masci

\section{Material development}

\subsection{The concept}

To start the process leading to effective food-based waste incorporation in a material, a matrix needs to be developed: most of these are obtained using polysaccharides waste, such as for example starch from potato skins, which is widely available and whose characteristics, in particular as regards hydrophilic nature, have also an effect on the mechanical properties of the bioplastic obtained (Dufresne et al., 2000; Ngobese et al., 2017).

For the materials obtained, often the term 'bioplastic' is used. As a matter of fact, in the two last decades there have been a number of proposals for transformation of food waste into bioplastics, for example in the work by Yu et al. (1998), using micro-organisms, and obtaining polyhydroxyalcanoate (PHA) polymers. This implies that these materials are comparable with polyolefins, such as polypropylene (PP) and polyethylene (PE). However, the procedure followed in this work is different, therefore 
cannot be thought as a bare material substitution. The idea is to lead in the long run to customisable products, which can have different colours and different aromas, the initial experiments aimed at this goal are the objective of this work. In particular, as far as colour is concerned, the materials are not mass-coloured, therefore will present different nuances and textures. Another objective, as mentioned above, is the possibility to produce the material with different perfumes using other waste: the polysaccharides matrix allows some transpiration of aromas. This is normally regarded as something to be avoided, as it allows the formation of mould and fungi. In this instance, however, added compounds would have an anti-mould effect, as it is for example the case with most leaves and plant extracts: the example of what done on bread is considered pertinent (Axel et al., 2017). Another possibility concerns the effect of light passing through the material, which enables some translucency across it, offered by the slight variability of colour over the material surface.

For all of the above reasons, the operation carried out in this work cannot be thought as a bare material substitution for polyolefins-derived plastics. In the last years, it has been considered that the introduction of bioplastics brings to significant variations of perspective with respect to traditional plastics. More specifically, this involves reaching a compromise among the capacity of materials, conventions about the particular product and its production route (Tonuk, 2018). On the other side, the possibilities offered by DIY materials (the terms 'bioplastics' becoming insufficiently descriptive at this point) about colour variations, aromas and translucency, together with the possibility to be directly moulded instead of injected, make these materials different from industrial bioplastics, such as poly(lactic acid) (PLA).

\subsection{The process}

The process for the manufacturing of the material started from the extraction of potato starch to produce the polysaccharide matrix. The solid part, including mainly starch and phenols (hereinafter referred as to 'starch'), was extracted after powdering potato skins, by mixing potato powder with de-ionised water and sieving the mixture through a $150 \mathrm{pm}$ mesh. A number of recipes were obtained, which included starch from potato skins, water and glycerin, the latter acting as a plasticiser for starch (Averous et al., 2001), vinegar and other components. The principle followed is that one ingredient at the time was only modified to verify its effect on the whole of the preparation.

Details on the different experiments are given in Table 1.

In practical terms, the recipes numbers 7 and 8 were used for the fabrication of bioplastics, as depicted in Figure 5. In these cases, a number of food colouring agents were also added, in particular natural principles were used, such as annatto (E160b) (a), chlorophyll (E140) (b), cochineal (E120) (d), anthocyanin (E163) (g) and spirulina extract (h). The only synthetic colour that has been used has been patent blue V (E131) (methylene blue) (c). This has been used because indigo blue, which is used in textile painting, is not recommendable though for purposes linked with food display (Steingruber, 2002). In addition, two examples of addition of colouring for aromatisation have been attempted, with cranberries extract (e) and sage and rosemary mashed leaves (f). A show of the coloUrs available was presented in the display in Figure 6. 
Table 1 Experiments carried out

\begin{tabular}{|c|c|c|}
\hline Test & Recipe (in parts) & Outcome \\
\hline 1 & $\begin{array}{l}7 \text { parts of water, } 1.5 \text { starch, } \\
1.5 \text { glycerol, } 1 \text { vinegar }\end{array}$ & $\begin{array}{l}\text { The ingredients were mixed continuously in the pan at } \\
\text { medium heat until some kind of milky consistency is } \\
\text { obtained. The mix becomes suddenly glue-like, due to } \\
\text { gelatinisation of starch, which heavily depends over the } \\
\text { amount of solutes, such as glycerol and vinegar (Evans } \\
\text { and Haisman, 1982). Following this, it is important to } \\
\text { mix energetically not to allow the residues to stick to the } \\
\text { pan. The material starts boiling, after which three minutes } \\
\text { are waited on until the material becomes completely } \\
\text { transparent. Depending on the moisture, it needs one day } \\
\text { to dry out or else it could be dried in an oven at } 65^{\circ} \mathrm{C} \text { for } \\
1.5 \text { hours. The use of a pressure cooker offered a material } \\
\text { with higher resistance. }\end{array}$ \\
\hline 2 & $\begin{array}{l}7 \text { water, } 1 \text { starch, } \\
1 \text { glycerol, } 1 \text { vinegar }\end{array}$ & $\begin{array}{l}\text { Since the first test had revealed the formation of a large } \\
\text { amount of mould. Therefore it was considered that the } \\
\text { cooking time needs to be longer by around five minutes } \\
\text { after boiling, which sorted the problem, and reducing the } \\
\text { amount of starch and at the same time the glycerol, } \\
\text { improved again visually the resistance to tensile loading, } \\
\text { but did not quite allow torsion yet. }\end{array}$ \\
\hline 3 & $\begin{array}{l}7 \text { water, } 1 \text { starch, } \\
1 \text { glycerol, } 1 \text { acetic acid }\end{array}$ & $\begin{array}{l}\text { The use of vinegar created problems in terms of the } \\
\text { strong odour the bioplastics presented, as well as being } \\
\text { excessively viscid: this was sorted out by replacing } \\
\text { vinegar by distilled acetic acid. }\end{array}$ \\
\hline 4 & $\begin{array}{l}7 \text { water, } 1 \text { starch } 1 \text { potato } \\
\text { flour, } 1 \text { glycerol, } 1 \text { sorbitol }\end{array}$ & $\begin{array}{l}\text { Here, some potato flour was acquired and mixed with } \\
\text { starch from potato skins and some more plasticiser was } \\
\text { added, this time sorbitol, which is deemed to improve } \\
\text { compactness of the bioplastic as well as absorbing some } \\
\text { water }\end{array}$ \\
\hline 5 & $\begin{array}{l}7 \text { water, } 1 \text { starch, } 1 \text { potato } \\
\text { flour, } 1 \text { wheat flour, } \\
1 \text { sorbitol }\end{array}$ & $\begin{array}{l}\text { The effect with sorbitol was even increased when } \\
\text { avoiding the presence of glycerol with it, the bioplastics } \\
\text { was in this case more resistant to tension and torsion, } \\
\text { however it degraded with time, becoming brittle and } \\
\text { showing gradual yellowing }\end{array}$ \\
\hline 6 & $\begin{array}{l}7 \text { water, } 1 \text { starch, } 1 \text { potato } \\
\text { flour, } 1 \text { glycerol, } 1 \text { lemon } \\
\text { juice }\end{array}$ & $\begin{array}{l}\text { To correct the odour, lemon was added, which proved } \\
\text { rather effective, however the material became sticky and } \\
\text { not very resistant. }\end{array}$ \\
\hline 7 & $\begin{array}{l}7 \text { water, } 1 \text { starch, } 1 \text { potato } \\
\text { flour, } 1 \text { sorbitol }\end{array}$ & $\begin{array}{l}\text { This is the final recipe, which proved quite effective for } \\
\text { the application, keeping some transparency. }\end{array}$ \\
\hline 8 & $\begin{array}{l}7 \text { water, } 1 \text { starch, } 1 \text { potato } \\
\text { flour, } 1 \text { sorbitol, plus filler } \\
\text { ( } 1 \text { part of mashed sage or } \\
\text { rosemary or } 1 \text { part of } \\
\text { cranberry extract) }\end{array}$ & $\begin{array}{l}\text { The addition of sage and rosemary improved the } \\
\text { resistance to the formation of mould without introducing } \\
\text { any particular odour and preventing yellowing. The } \\
\text { bioplastic had still some transparency with both fillers } \\
\text { added. }\end{array}$ \\
\hline
\end{tabular}

The objective thickness was $2.5 \mathrm{~mm}$. This was obtained with an accuracy of $\pm 0.3 \mathrm{~mm}$, which was considered sufficient for the development of the intended object. Natural curing of the polymer (ambient temperature for one day) yielded a shrinkage in the region of $10 \pm 2 \%$, compared to around $12.5 \pm 1.5 \%$ obtained with accelerated curing (in oven at $65^{\circ} \mathrm{C}$ for 1.5 hours). After curing, the flat regions of the samples were 
subjected to Shore D hardness tests. The results obtained were deemed sufficient for the application envisaged, more specifically being $24 \pm 2$ for naturally cured material and $26 \pm 2.5$ for naturally cured material. For the application envisaged, it was also essential to create holes in the bioplastic sheets: this proved feasible both using a belt hole puncher, for holes up to $3 \mathrm{~mm}$ diameter, and a paper hole punch to obtain holes of $4.5 \mathrm{~mm}$. In both cases, holes with clean edges were obtained. Moreover, it was necessary to glue to each other sheets of bioplastic, which was achieved by adding some glue-like bioplastic according to the recipe nr. 7, though starch plasticisation is obtained with a shorter heating time, which prevented excessive consolidation, not to lead to material brittleness (Scandola et al., 1998).

Figure 5 DIY material coloured with different nuances (see online version for colours)

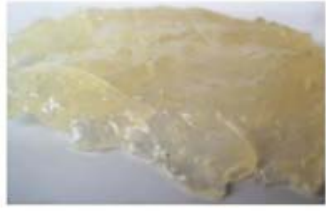

(a)

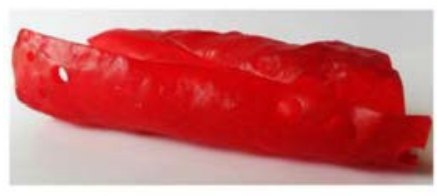

(d)

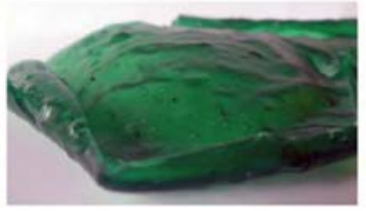

(b)

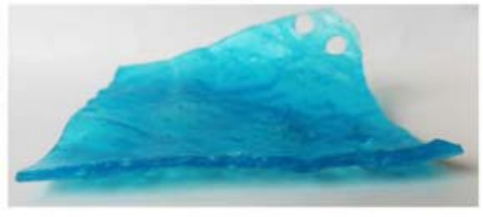

(c)

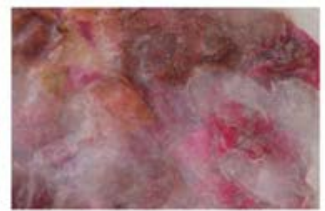

(e)

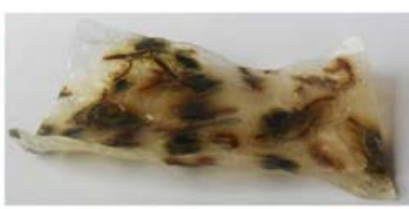

(f)

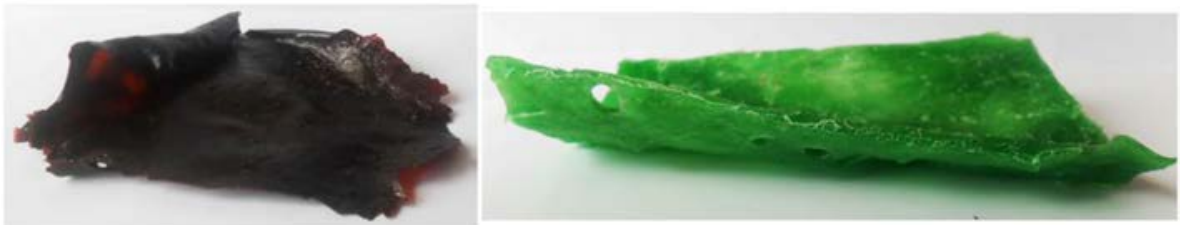

(g)

(h)

Figure 6 Show of different colours obtained (see online version for colours)

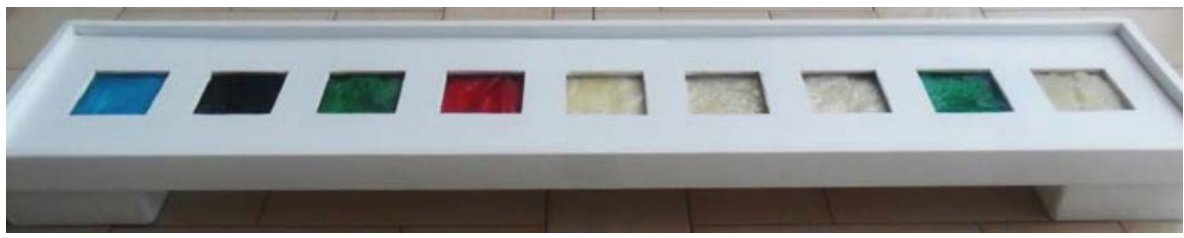




\section{The project}

\subsection{Some examples for inspiration}

Displays are aimed to present products that are on sale allowing for their immediate and direct picking up. Some objects were analysed for comparison, mainly in the Italian agricultural context: among these a few examples are shown, from which a few characteristics are selected, which appear to be essential to the specific nature of food displays. Oleo is a self-promotion display for $75 \mathrm{cl}$. oil bottles, which communicates the nature of the product, with a strategy that mimics the process of selecting olives for producing olive oil: in practice, the display allows choosing from which shutter (branch) the bottle (olive) can be collected. It has an extractable element, useful for appetisers. When closed, it is a kind of totem, yet its shape can be modulated as a function of stocking needs. The project is the result of the workshop carried out in Sora, Italy (March 2012) and proposed by Associazione Distretto del Design (Figure 7).

Figure 7 Oleo system for the exposure of oil bottles (see online version for colours)
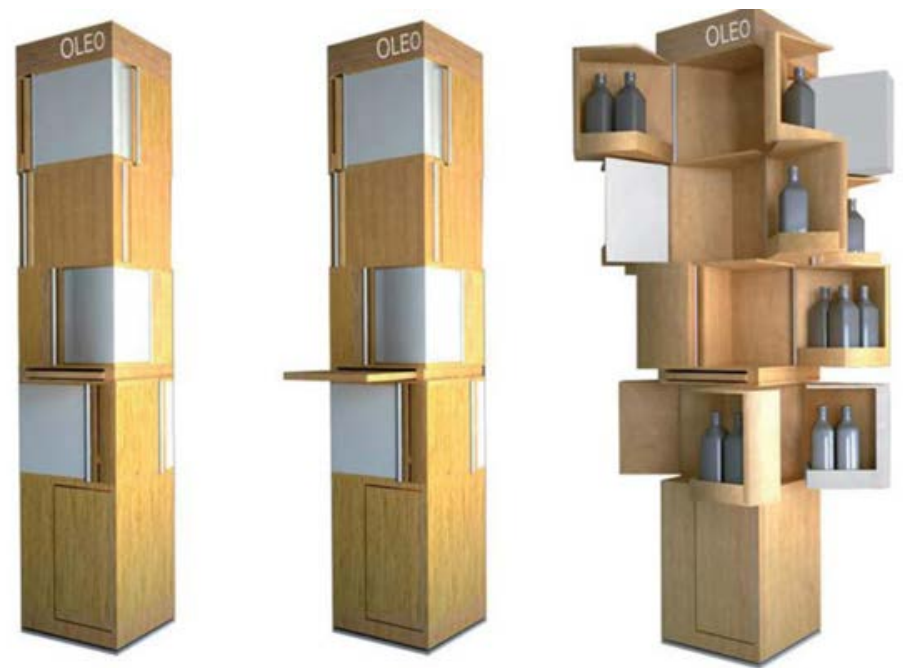

Mangier (Figure 8) by Stephanie Marin and Mauro Colagreco (exposed in the occasion of the Living Party of the National Art Center in Nice, France) is again a tree, but arranged in the way to display and introduce food items during your meals, be these cocktails, buffets or garden parties. Using cocktail sticks, appetisers, radishes, strawberries, candies can be skewered. The guests collect the food directly from the 'tree', making a reference to ancient times, when fruits, such as olives, were directly consumed by picking them up from the tree. This can be interpreted as a simple and natural gesture, a kind of 'trait d'union' between the present and the past. It is a food display in solid beech wood fully recyclable and in natural colours. Its characteristics involve the presence of 20 stands. Mangier is washable with water using a damp sponge and can be possibly polished using pumice stone. 
Figure 8 Mangier ('arbre a manger', eating tree) (see online version for colours)

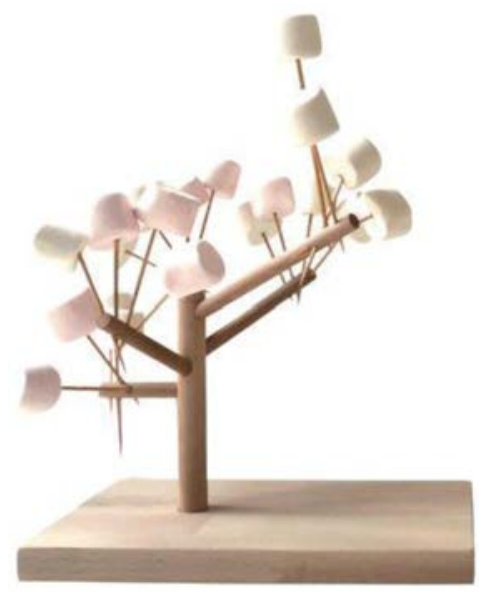

While on one side the tree-branch structure, coupled with self-service concepts, appears to be effective for food, it is preferable that the material used, such as polymethylmetacrylate (PMMA), is able to offer transparency, hence giving the possibility to clearly observe displayed food. This is the case for example of displays by Geprom for candies, sweets, cereals, coffee, sugar and spices with different solutions in terms of cover and possibilities of recharging (from above or from the front side). Another essential idea is once again the limited space consumption, thence the possibility of superposing different 'layers' or 'levels'. This is exploited for example in an effective way in a PMMA display for ice cream cones, shown in Figure 9, where steps are designed to correctly visualise food products.

Figure 9 System for the distribution of ice cream cones (see online version for colours)

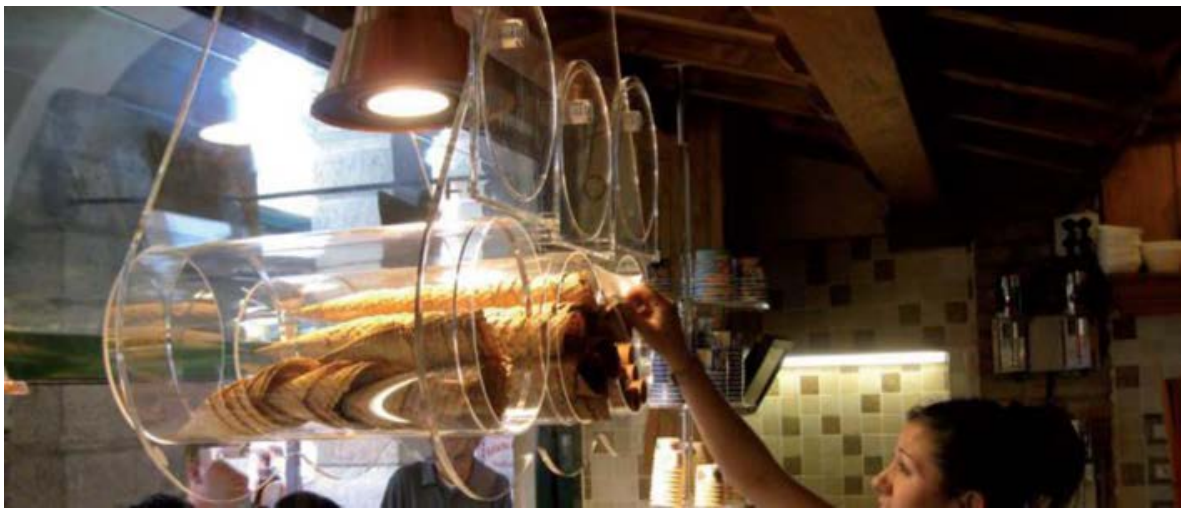

A further example is offered from HiCellar by Marco Stano (Figure 10), which is an innovative communication tool, immediate, high-tech (with touch screen navigation by iPad) and easy to be used, allowing the user to make choice without any need to ask for advice. The design structure is based on wood frames, with bottle holder, once again 
realised in PMMA and focused on the use of the iPad, on which physically the stand-alone application is installed. The laminate on the background gives hints on the characteristics of the exposed product.

Figure 10 Hi cellar: system for the show of wine bottles along a wall with digital interface (see online version for colours)

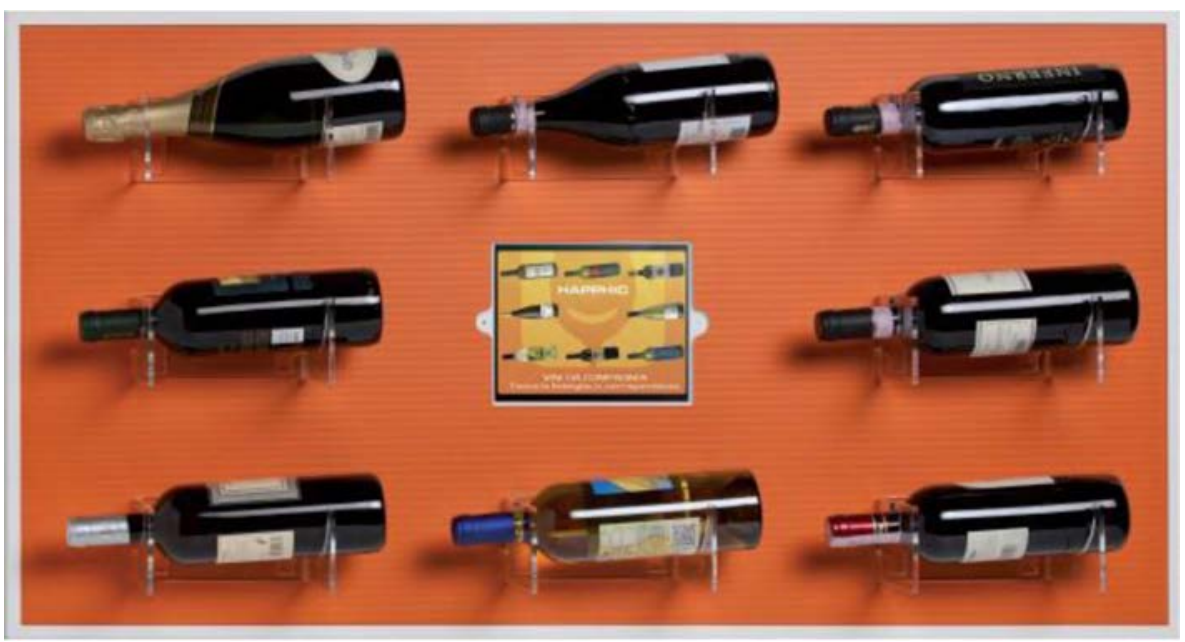

\subsection{Realisation}

It is clear therefore that, since bioplastics is only partially transparent, the colours and also the personalisation with fragments of leaves, such as in the case of sage and rosemary, which have also the operational sense of anti-mould fillers, have a non-negligible significance. Concentrating on displays for fruits, the vertical character and the fact to be placed against the wall can also suggest a resemblance with climbing ivy, which is archetypal in the Italian agritourism context (Figure 11). This vertical fruit display is composed by two material strips united in some points, which can achieved for small structures directly by moulding together the two strips. The general idea is forming rows with compartments, in which the different fruits are inserted, creating finally a 'fruit wall', which can be coloured and personalised in different ways. Details of parts of the display are given in Figure 12.

In the case of larger structures, the two strips are attached by the same material, only with a slightly different 'recipe, as reported above, to a steel bar that is fixed to the wall, and they are furthermore easily removable, so that when the material is deteriorated they are replaced with two similar strips. A closer view of the way in which they are fixed to the wall, by the insertion of small rubber elements, is given in Figure 13. The worn out strips, being compostable, can be instead inserted in flower pots at end-of-life, being free to decompose without the terrain becoming sterile. In this way, they allow visitors considering the biodegradation process, which can have also significance in terms of learning (thinking for example to the presence of children in the farm) (Figure 14). 
Figure 11 Bioplastic wall for fruits show (see online version for colours)

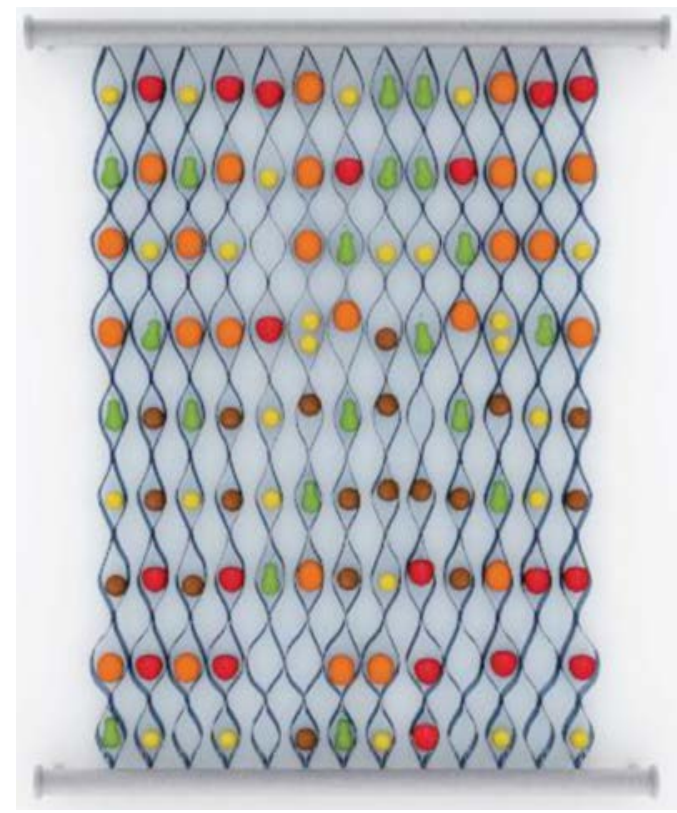

Figure 12 Details of the bioplastic wall (see online version for colours)
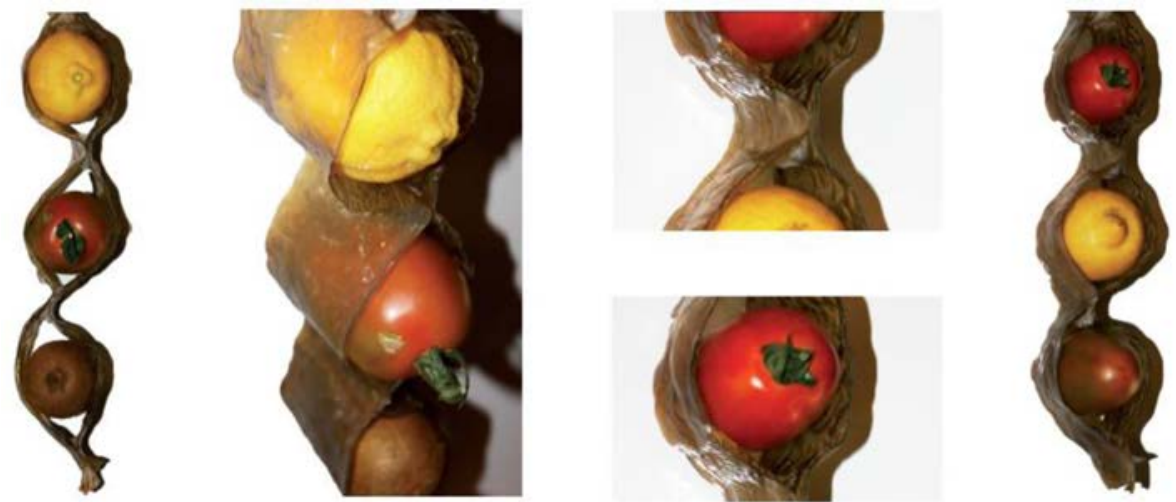

A further development of this concept would ideally be the production through DIY material of a sort of large basket for fruit storage. Its geometry is semispherical with holes of different dimensions on the whole surface, in order to let the dirt accumulating so to be easily removed and let the air through so that the fruit will not get spoiled at the bottom of the basket. The holes would be more precisely obtained by the adoption of a fitted mould: examples of this basket are reported in Figure 15, while its setting together with the vertical fruit display is shown in Figure 16. 
Figure 13 Details of the junction system to the wall (see online version for colours)

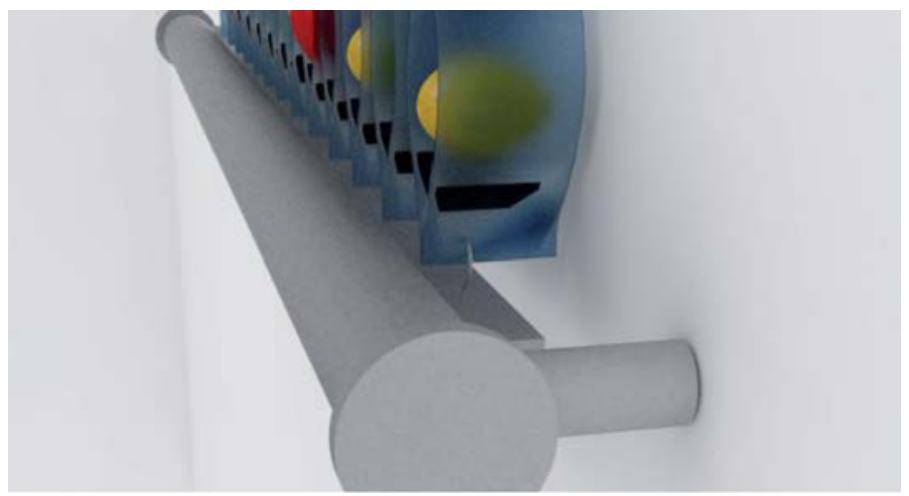

Figure 14 Rendering of 'fruit wall' setting (see online version for colours)

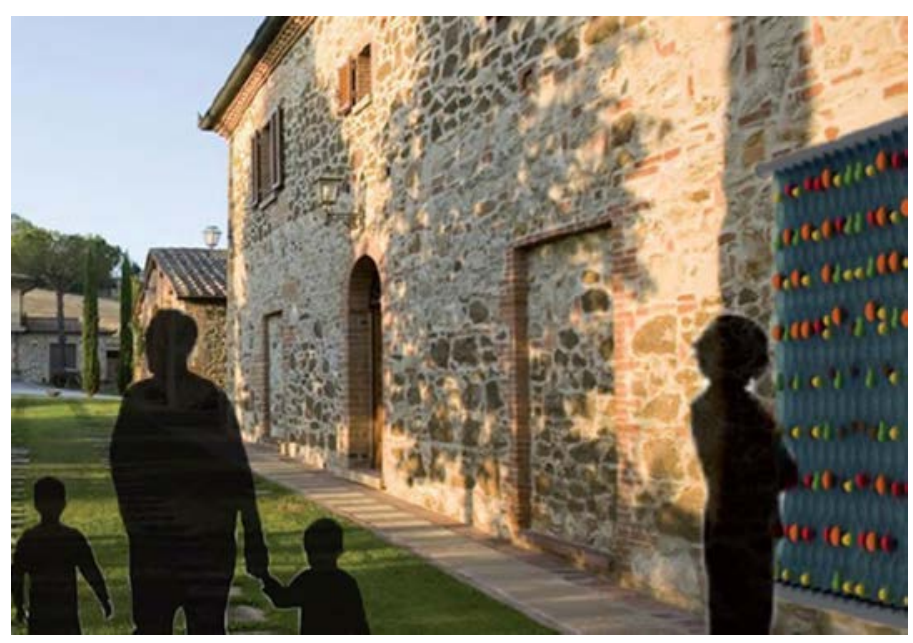

Figure 15 Bioplastics bowls for fruits exposure (see online version for colours)

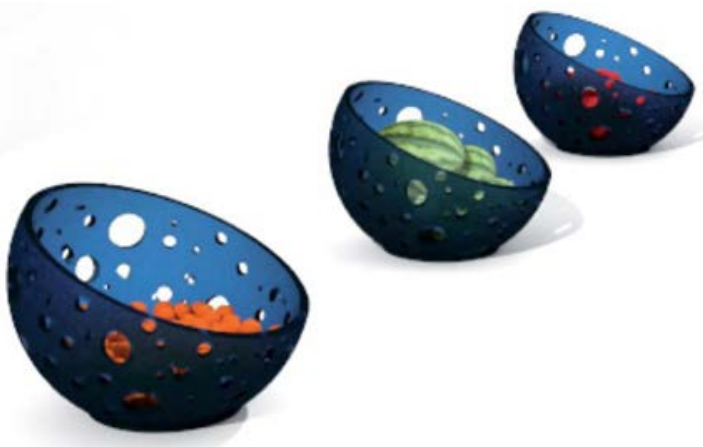


Figure 16 Rendering of bioplastic bowls exposure in a countryside setting (see online version for colours)

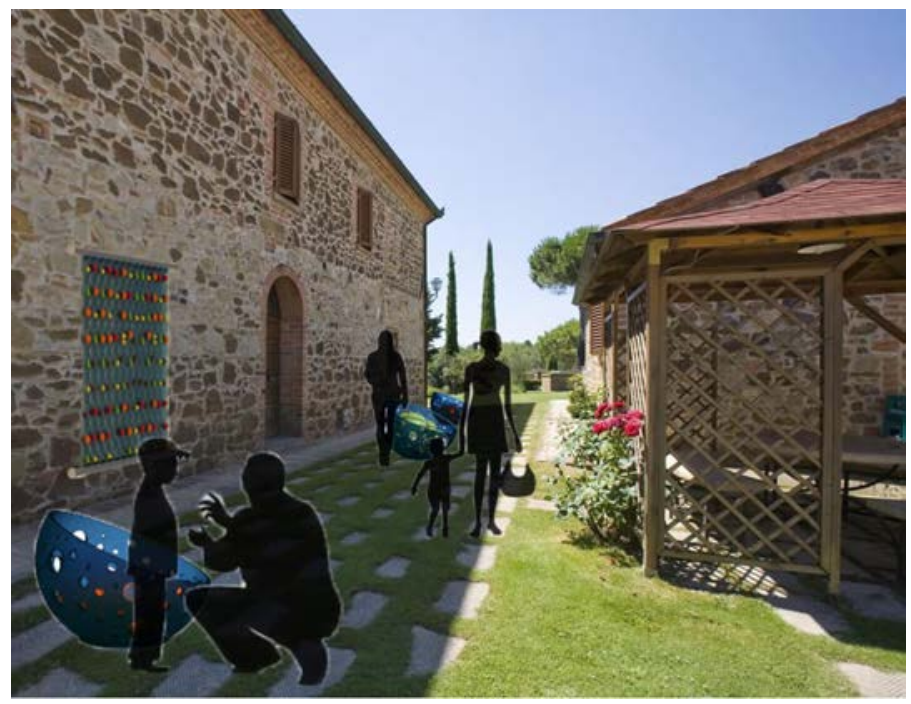

\section{Conclusions}

This work offered some indications on the prospective production of DIY materials from a 'material tinkering' experiment, based on potato skins with expressive possibilities (colours, aromas, translucency), in the specific case to be applied to obtain a wall display for fruits. Typically, DIY materials are moulded into specifically fabricated moulds: in this particular case, the technical issues of joining two layers of material through the same material, only with a slightly different 'recipe', was also solved and the possibility to colour it through natural pigments used in food colouration offered also a substantial success.

In the specific case to which this purposely developed material was applied, i.e., a wall display for fruits, it may be observed that this could prospectively be improved, at the same time preserving the characteristics of waste, especially as the result of the variability of dimensions of particles, of colour nuances, of textures, etc. Inclusion of other types of food-derived waste, such as leaves and extracts, would also allow reducing degradation and work as an anti-mould strategy. Finally, the integration of this object in the same production system (food chain) would be in the long run preferable not only for easier marketability, but also to allow easier collection of waste for the purpose (e.g., exhaust coffee grounds from coffee shops, restaurants, etc.). 


\section{References}

Arvanitoyannis, I.S., Ladas, D. and Mavromatis, A. (2006) 'Wine waste treatment methodology', International Journal of Food Science and Technology, Vol. 41, No. 10, pp.1117-1151.

Ashby, M.F., Shercliff, H. and Cebon, D. (2013) Materials: Engineering, Science, Processing and Design, 3rd ed., 784pp., Butterworth-Heinemann, Oxford, ISBN 9780080982816.

Averous, L., Fringant, C. and Moro, L. (2001) 'Plasticized starch-cellulose interactions in polysaccharide composites', Polymer, Vol. 42, No. 15, pp.6565-6572.

Axel, C., Zannini, E. and Arendt, E.K. (2017) 'Mold spoilage of bread and its bio-preservation: a review of current strategies for bread shelf life extension', Critical Reviews in Food Science and Nutrition, Vol. 57, No. 16, pp.3528-3542.

Bayer, I.S., Guzman-Puyol, S., Heredia-Guerrero, J.A., Ceseracciu, L., Pignatelli, F., Ruffilli, R., Cingolani, R. and Athanassiou, A. (2014) 'Transformation of edible vegetable waste into bioplastics’, Macromolecules, Vol. 47, No. 15, pp.5135-5143.

Bodzay, B. and Banhegyi, G. (2016) 'Polymer waste: controlled breakdown or recycling?', International Journal of Design Sciences and Technology, Vol. 22, No. 2, pp.109-138.

Dufresne, A., Dupeyre, D. and Vignon, M.R. (2000) 'Cellulose microfibrils from potato tuber cells: processing and characterization of starch-cellulose microfibril composites', Journal of Applied Polymer Science, Vol. 76, No. 14, pp.2080-2092.

Evans, D. and Haisman, D.R. (1982) 'The effect of solutes on the gelatinization temperature range of potato starch', Starch, Vol. 34, No. 7, pp.224-231.

Ngobese, N.Z., Workneh, T.S., Alimi, B.A. and Tesfay, S.F. (2017) 'Nutrient composition and starch characteristics of eight European potato cultivars cultivated in South Africa', Journal of Food Composition and Analysis, January, Vol. 55, pp.1-11.

Oxman, N. (2010) 'Structuring materiality: design fabrication of heterogeneous materials', Architectural Design, Vol. 80, No. 4, pp.78-85.

Parisi, S., Rognoli, V. and Sonneveld, M. (2017) 'Material tinkering. An inspirational approach for experiential learning and envisioning in product design education', in The Design Journal, Vol. 20, Sup. 1, Di Lucchio, L., Imbesi, L. and Atkinson, P. (Eds.): Design for Next: Proceedings of the 12th European Academy of Design Conference, Sapienza University of Rome, 12-14 April, pp.S1167-S1184.

Piemonte, V. (2011) 'Bioplastic wastes: the best final disposition for energy saving', Journal of Polymers and the Environment, Vol. 19, No. 4, pp.988-994.

Rognoli, V., Bianchini, M., Maffei, S. and Karana, E. (2015) 'DIY materials', Materials \& Design, 5 December, Vol. 86, pp.692-702.

Santulli, C. and Lucibello, S. (2018) 'Experience of material tinkering from waste in the year 3-year 5 primary school age range as an introduction to design and sustainability', Journal of Education and Practice, Vol. 9, No. 18, pp.115-126.

Scandola, M., Finelli, I., Sarti, B., Mergaert, J., Swings, J., Ruffieux, K., Wintermantel, E., Boelens, J., De Wilde, B., Muller, W.R., Schafer, A., Fink, A.B. and Bader, H.G. (1998) 'Biodegradation of a starch containing thermoplastic in standardized test systems', Journal of Macromolecular Science, Part A, Vol. 35, No. 4, pp.89-608.

Steingruber, E. (2002) 'Indigo and indigo colorants', Ullmann's Encyclopedia of Industrial Chemistry, Wiley, DOI: 10.1002/14356007.a14_149.pub2.

Tonuk, D. (2018) 'Materials as temporally specific phenomena: specialization and compromise in bioplastics production', Journal of Material Culture, Vol. 23, No. 1, pp.114-130.

Yu, P.H., Chu, H., Huang, A.L., Lo, W. and Chen, G.Q. (1998) 'Conversion of food industrial wastes into bioplastics’, Applied Biochemistry and Biotechnology, Vol. 70, No. 1, pp.603-614. 


\section{Websites}

AgriDust [online] https://www.behance.net/gallerv/24616719/agridust-biodegradable-material

Algaevase [online] http://mandydenelzen.com/algae-vase/

Anacleto from UseDesign [online] http://www.usedesign.it/anacleto-by-luca-scarpellini/

Artichair [online] http://kizisstudio.com/atichairdining/

Bioplastic Fantastic [online] http://iohannaschmeer.com/bioplasticfantastic

Ecovative [online] http://www.ecovativedesign.com/

Geprom Displays [online] http://docplayer.it/27936988-Ws-led-g-eprom-d-e-s-i-g-n-espositoriluminosi-illuminated-display-stands.html

Gumdrop [online] http://www.gumipod.com/chewing-gum-litter-problem-costs-brits-millions/

HiCellar [online] http://www.alternativasostenibile.it/articolo/nasce-hicellar-il-modorivoluzionario-per-esporre-il-vino-0608.html

Jelloware [online] https://www.kickstarter.com/proiects/thewayweseetheworld/iellowarebiodegradable-edible-cups

Mangier [online] https://www.madeindesign.it/prod-espositore-per-alimenti-mangier-arbre-amanger-albero-da-mangiare-di-smarin-refmangier-albert.html

Metabolic Factory [online] http://www.designboom.com/design/human-hair-bioplastic-themetabolic-factory-by-thomas-vaiNy/

NewspaperWood [online] http://www.newspaperwood.com/

Oleo [online] http://myfoodesign.blogspot.it/2012/10/oleo-il-mio-espositore.html

Orange Fiber [online] http://www.orangefiber.it/en/

PaperMilk [online] http://www.susannabonati.it/papermilk/

Perpetua [online] http://www.uncomag.com/interviste/578-susanna-martucci-perpetua/

Pinatex [online] http://www.ananas-anam.com/pinatex/

Recycle Series [online] http://www.domusweb.it/en/news/2015/04/Q2/bentu_design_recycle_ series.html

Spray-on [online] https://www.theguardian.com/science/2010/sep/16/sprav-on-clothing-t-shirt

Yarn from old newspapers [online] https://www.dezeen.com/2007/10/21/yarn-from-oldnewspapers-bv-greetje-van-tiem/ 